Michael Joseph C. David, MD'

Gil M. Vicente, MD ${ }^{1,2}$

Antonio H. Chua, MD ${ }^{1,3}$

'Department of Otorhinolaryngology Head and Neck Surgery

Jose R. Reyes Memorial Medical Center

${ }^{2}$ Department of Otorhinolaryngology Head and Neck Surgery

St. Luke's Medical Center

${ }^{3}$ Department of Otorhinolaryngology Head and Neck Surgery

University of the East Ramon Magsaysay

Memorial Medical Center
Correspondence: Michael Joseph C. David, MD Department of ENT-HNS

Jose R. Reyes Memorial Medical Center

San Lazaro Compound, Rizal Avenue

Sta. Cruz, Manila 1003

Philippines

Phone/Fax: (632)743 6921

Reprints will not be available from the author.

No funding support was received for this study. The authors signed disclosures that they have no proprietary or financial interest with an organization that may have a direct interest in the subject matter of this manuscript, or in any product used or cited in this study.

Presented at Descriptive Research Contest, Philippine Society of Otolaryngology

Head and Neck Surgery,

Jade Valley Restaurant, September 25, 2008

\section{Pediatric Endoscopic Sinus Surgery in a Tertiary Government Hospital: Patient Profile and Surgical Indications}

ABSTRACT
Objective: To describe the clinical and demographic profile of patients who underwent pediatric Endoscopic Sinus Surgery (ESS) and the indications for which the procedure was performed.

\section{Methods:}

Design: Cross-sectional Study

Setting: Tertiary Government Hospital

Subjects: Using the medical record registry, all patients below 18 years of age who underwent ESS under the Department of Otorhinolaryngology - Head and Neck Surgery of a tertiary government hospital in Metro Manila between December 31, 1999 and January 1, 2008 were reviewed. The age, sex, clinical presentation indications for doing ESS and extent of surgery done were described. The Lund Mackay Grading for nasal polyposis and Scoring for sinusitis were also applied and cross-referenced.

Results: Twenty-seven children aged 7 to 17 years underwent ESS. The mean age was 12.9 years with most ( 15 patients) belonging to the adolescent age group (13-17 years). Male to female ratio was 1.45:1. The mean interval from onset of symptoms to the first outpatient consultation was 1.5 years; the most common presenting symptoms were nasal obstruction (85.2\%) and discharge (59.3\%).

All of the patients who underwent pediatric ESS had chronic rhinosinusitis: either with nasal polyposis (85.2\%), an antrochoanal polyp (11.1\%) or both (3.7\%). The Lund Mackay Grading for nasal polyps and sinusitis scores were cross-referenced: patients with larger, grade III nasal polyps tended to have more extensive sinus disease than those with grade II polyps. On their first consultation, the patients tended to present with extensive nasal polyp and sinus disease indicating the need for surgery.

All patients with CRS and nasal polyposis underwent polypectomy with ethmoidectomy, uncinectomy and maxillary antrostomy, with additional frontal sinusotomy for a 17-year-old male and a 17-year-old female, both with grade 3 polyposis. The three patients who had antrochoanal polyps underwent polypectomy with uncinectomy and maxillary antrostomy. There were no operative complications such as cerebrospinal fluid leak and orbital injury reported. 
Conclusion: Most of the patients who underwent pediatric ESS were older children who were brought for consultation with long-standing, extensive nasal polyp and sinus disease or with antrochoanal polyps, necessitating surgical management. Patients with larger polyps tended to have more extensive sinus disease. They all underwent conservative surgery, with extent of the procedure limited to the extent of the disease present. Efforts to raise public awareness about chronic rhinosinusitis and nasal polyposis in children may result in seeing such cases at an earlier, conservatively treatable stage.

Key words: Pediatric Endoscopic Sinus Surgery, Nasal Polyposis in Children

Endoscopic Sinus Surgery (ESS) is a surgical procedure for restoration of physiological function to the drainage pathways of the paranasal sinuses. Since Gross et al introduced ESS for children in 1989, it has rapidly gained acceptance as the primary surgical procedure for the treatment of chronic rhinosinusitis (CRS) and nasal polyposis in pediatric patients. ${ }^{1,2}$ The reported success rates range from $76 \%$ to $97.5 \%$ following improvements in surgical techniques and the development of optical equipment and instruments. ${ }^{3}$

Initial surgical indications for pediatric ESS were broad, applying adult ESS indications to the pediatric population without evidence-based data. ${ }^{3}$ Early studies of pediatric ESS were often retrospective without comparison to a medically treated or non-treated group. A paradigm shift occurred when prospective studies indicated that medical therapy was an effective approach to treatment for CRS in the pediatric population. ${ }^{4}$

A meta-analysis of eight published articles reported positive outcomes for pediatric ESS ranging from $77 \%$ to $100 \%$ with a pooled positive outcome in $88.4 \%$ of children., ${ }^{5,6,7}$

As with adults, ESS for children with CRS is usually reserved for failure of maximal medical management. The definition of optimal medical management, as well as indications and degree of surgical intervention, however, are less clearly defined in children. Clary described a surgical candidate as a child with normal immune function testing who has failed to respond to both maximal medical therapy and adenoidectomy and meets criteria of chronic rhinosinusitis by history and CT findings. ${ }^{8}$ Consensus guidelines list nine indications for ESS in children: complete nasal obstruction in cystic fibrosis caused by massive polyposis or closure of the nose by medialization of the lateral nasal wall, antrochoanal polyps, intracranial complications of sinus disease, mucoceles and mucopyoceles, orbital abscesses, traumatic injury to the optic canal, dacrocystorhinitis secondary to sinusitis, fungal sinusitis and some meningoencephaloceles. ${ }^{9}$

Unfortunately, pediatric ESS is not simply adult FESS in a smaller patient. When surgery is indicated, it usually remains conservative, consisting of a maxillary antrostomy and anterior ethmoidectomy. Children pose special operative challenges because of the small anatomy and differences in underlying causes of sinus disease. The conservative ESS technique dictates that the extent of the procedure performed is proportional to the extent of the disease present. This limited technique of ESS was proven to be an effective treatment modality for severe, medically-refractory CRS in children. ${ }^{10}$

The overall incidence of nasal polyps in children is $0.1 \%$; the prevalence of CRS with nasal polyps is likewise $0.1 \%{ }^{11}$. Nasal polyps usually are manifested after the age of 12 years, with affected males outnumbering females two to one. ${ }^{11,12}$ The reported prevalence of surgically amenable sinus and polyp disease in children varies from 1 to $5 \% .^{12}$

This paper aims to determine the clinical and demographic profile of pediatric patients who underwent ESS at the Jose R. Reyes Memorial Medical Center between December 31, 1999 and January 1,2008 . Specifically, it aims to describe their clinical presentation, symptom duration, radiographic and endoscopic findings, extent of surgery done and to review the indications and/or disease for which pediatric ESS was performed.

\section{METHODS}

Design: Cross-sectional Study

Setting: Tertiary Government Hospital

Subjects: Using the medical record registry, the records of all patients below 18 years of age who underwent ESS under the Department of Otorhinolaryngology - Head and Neck Surgery of a tertiary government hospital in Metro Manila between December 31, 1999 and January 1, 2008 were retrospectively reviewed (Appendix A). The age, sex, geographic distribution, clinical presentation and indications for doing ESS were described. Radiographic and endoscopic findings were recorded and the Lund MacKay Grading for nasal polyposis and Scoring for sinusitis (Appendix B) were used to classify the endoscopic and radiographic findings and cross-referenced. ${ }^{13,14}$

\section{RESULTS}

Twenty seven (27) children aged 7 to 17 years underwent ESS during the 8-year period. The mean age was 12.9 years, with most (15 patients) belonging to the adolescent age group (13-17 years). Except for a 7-year-old with nasal polyposis, the four youngest patients (ages 8, 9, 9 and 10) all had antrochoanal polyps. Sixteen were male and 11 female, with a $1.45: 1$ male to female ratio.

The mean interval from the onset of symptoms to the first outpatient consultation was 1.5 years. Patients with nasal polyposis and CRS started to have symptoms at 11.4 years on the average and they were first brought for consultation at 12.9 years. Those with antrochoanal polyposis were seen at an 
ORIGINAL ARTICLES

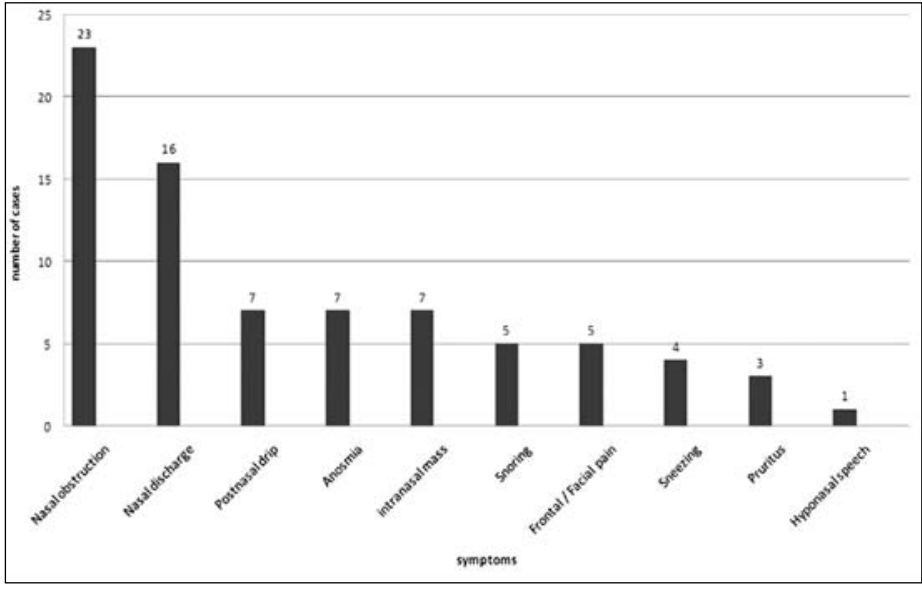

Figure 1. Presenting Symptoms Reported During the First Outpatient Consultation

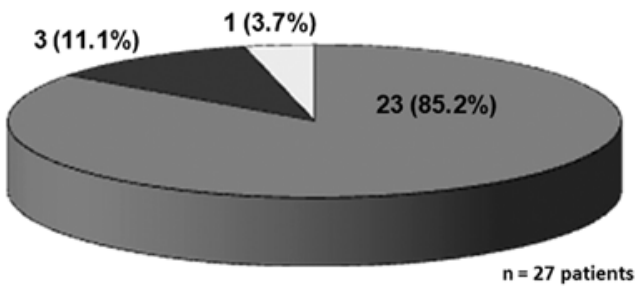

a Nasal Polyposis with CRS

Antrochoanal polyp with CRS

$\square$ Antrochoanal polyp with Antrochoanal polypwith
nasal polyposis and CRS

Figure 2. Clinical Diagnosis Prior to Pediatric ESS

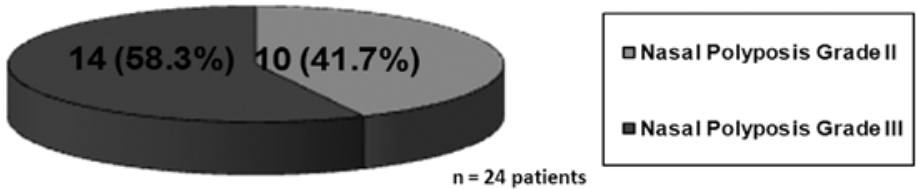

Figure 3. Lund Mackay Grading of Nasal Polyps in Patients with Nasal Polyposis

\begin{tabular}{|c|c|c|c|}
\hline \multirow{2}{*}{$\begin{array}{l}\text { Lund Mackay } \\
\text { Score for } \\
\text { Sinusitis }\end{array}$} & \multicolumn{3}{|c|}{ \# of cases } \\
\hline & $\begin{array}{c}\text { Grade I } \\
\text { polyposis }\end{array}$ & $\begin{array}{c}\text { Grade II } \\
\text { polyposis }\end{array}$ & $\begin{array}{l}\text { Grade III } \\
\text { polyposis }\end{array}$ \\
\hline 12 & 0 & 2 & 0 \\
\hline 14 & 0 & 2 & 2 \\
\hline 16 & 0 & 3 & 2 \\
\hline 18 & 0 & 2 & 2 \\
\hline 19 & 0 & 0 & 5 \\
\hline 20 & 0 & 0 & 2 \\
\hline 21 & 0 & 0 & 1 \\
\hline
\end{tabular}

Figure 4. Correlation of the Lund Mackay Scores for Sinusitis and Polyp Grading average age of 9 years, but started to have symptoms around the age of 7.5 years.

The most common presenting symptoms were nasal obstruction $(23 / 27$ or $85.2 \%)$ and nasal discharge $(16 / 27$ or $59.3 \%)$. Seven (25.9\%) of the patients had anosmia, postnasal drip and/or palpable intranasal masses (Figure 1).

All of the patients had CRS with nasal polyposis in 23 (85.2\%), with an antrochoanal polyp in $3(11.1 \%)$, or with both in 1 patient (Figure 2). On nasal endoscopy, 14 (58.3\%) of those with nasal polyposis had grade III polyps and $10(41.7 \%)$ had grade II polyps by Lund Mackay Grading (Figure 3). Polyp grading was compared with the Lund Mackay Scores for sinusitis (Figure 4). Patients with higher grade polyps also had more extensive paranasal sinus disease: those with grade II polyps had a mean score of 16 , while those with grade III polyps had a mean sinusitis score of 18.6.

All patients (24) with CRS and nasal polyposis underwent polypectomy with ethmoidectomy, uncinectomy and maxillary antrostomy with additional frontal sinusotomy for a 17-year-old male and a 17-year-old female, both with grade 3 polyposis. The three patients who had antrochoanal polyps underwent polypectomy with uncinectomy and maxillary antrostomy. There were no operative complications such as cerebrospinal fluid leak nor orbital injury reported.

\section{DISCUSSION}

Nasal polyposis is an inflammatory chronic disease of the upper respiratory tract of unknown etiology although it may be associated with cystic fibrosis. In one recent study, the prevalence of nasal polyps in 211 adult patients with cystic fibrosis was $37 \% .^{15}$ However, cystic fibrosis is an autosomal recessive condition affecting mostly Caucasians and it is very uncommon in Filipinos.

The reported prevalence of surgically amenable sinus and polyp disease in children varies from 1 to $5 \%^{12}$. Nasal polyps usually are manifested after the age of 12 years, with affected males outnumbering females two to one. ${ }^{11,12}$ Similarly in this study, pediatric ESS was found to be mostly performed on older children with nasal polyposis and CRS. Our survey had a male to female ratio of 1.45:1.

The mean interval from the onset of symptoms to the first outpatient consultation was 1.5 years. The tolerance for months or years of persistent nasal obstruction and discharge may account for the relatively advanced polyp and sinus disease on initial consultation. The children may have been too young to give importance to the disease and related symptoms or unable to express themselves adequately. ${ }^{16}$ In our setting, socioeconomic constraints also affect access to health care and must be considered with such delays in consultation.

All patients with grade II to III nasal polyposis had equally extensive sinus disease. According to a study done by Hopkins et 
$a l$, sinusitis scores increased with increasing grade of polyposis. ${ }^{17}$ In our patients, Lund Mackay Grading for nasal polyps were directly proportional with sinusitis scores as demonstrated by computed tomography of the paranasal sinuses. Patients with larger, grade III nasal polyps tended to have more extensive sinus disease than those with grade II polyps.

Following the conservative ESS technique, the extent of surgery for majority of cases was limited to polypectomy, ethmoidectomy, uncinectomy and maxillary antrostomy. Frontal sinusotomy was only considered an option for 2 of the older patients, both of which had extensive sinus disease.

Most of the patients who underwent pediatric ESS were older children who were brought for consultation with long-standing, extensive nasal polyp and sinus disease or with antrochoanal polyps, necessitating surgical management. They all underwent conservative surgery, with extent of the procedure limited to the extent of the disease present. Efforts to raise public awareness about chronic rhinosinusitis and nasal polyposis in children may result in seeing such cases at an earlier, conservatively treatable stage.

Appendix A. Patient Demographics

\begin{tabular}{|c|c|c|c|c|c|c|c|}
\hline PATIENT & AGE & SEX & ADDRESS & DIAGNOSIS & $\begin{array}{l}\text { POLYP } \\
\text { GRADE }\end{array}$ & EXTENT OF SURGERY & $\begin{array}{c}\text { OPERATIVE } \\
\text { COMPLICATIONS }\end{array}$ \\
\hline 1 & 14 & M & Valenzuela & Nasal Polyposis & $\|$ & Ethmoidectomy, uncinectomy, maxillary antrostomy & None \\
\hline 2 & 14 & $\mathrm{~F}$ & Cavite & Nasal Polyposis & III & Ethmoidectomy, uncinectomy, maxillary antrostomy & None \\
\hline 3 & 9 & $\mathrm{~F}$ & Manila & Antrochoanal polyp with nasal polyposis & III & Ethmoidectomy, uncinectomy, maxillary antrostomy & None \\
\hline 4 & 15 & M & Quezon City & Nasal polyposis & III & Ethmoidectomy, uncinectomy, maxillary antrostomy & None \\
\hline 5 & 12 & $\mathrm{~F}$ & Manila & Nasal Polyposis & $\|$ & Ethmoidectomy, uncinectomy, maxillary antrostomy & None \\
\hline 6 & 12 & M & Quezon City & Nasal polyposis & $\|$ & Ethmoidectomy, uncinectomy, maxillary antrostomy & None \\
\hline 7 & 16 & M & Bulacan & Nasal Polyposis & $\|$ & Ethmoidectomy, uncinectomy, maxillary antrostomy & None \\
\hline 8 & 14 & $\mathrm{~F}$ & Quezon Prov. & Nasal polyposis & III & Ethmoidectomy, uncinectomy, maxillary antrostomy & None \\
\hline 9 & 17 & M & Quezon City & Nasal Polyposis & III & Ethmoidectomy, uncinectomy, maxillary antrostomy, frontal sinusotomy & None \\
\hline 10 & 8 & M & Valenzuela & Antrochoanal polyp & $\mathrm{n} / \mathrm{a}$ & uncinectomy, maxillary antrostomy & None \\
\hline 11 & 16 & M & Valenzuela & Nasal Polyposis & III & Ethmoidectomy, uncinectomy, maxillary antrostomy & None \\
\hline 12 & 17 & $\mathrm{~F}$ & Manila & Nasal Polyposis & III & Ethmoidectomy, uncinectomy, maxillary antrostomy, frontal sinusotomy & None \\
\hline 13 & 12 & M & Manila & Nasal Polyposis & III & Ethmoidectomy, uncinectomy, maxillary antrostomy & None \\
\hline 14 & 11 & M & Bulacan & Nasal Polyposis & $\|$ & Ethmoidectomy, uncinectomy, maxillary antrostomy & None \\
\hline 15 & 15 & $\mathrm{~F}$ & Manila & Nasal polyposis & $\|$ & Ethmoidectomy, uncinectomy, maxillary antrostomy & None \\
\hline 16 & 10 & M & Valenzuela & Nasal Polyposis & $\|$ & Ethmoidectomy, uncinectomy, maxillary antrostomy & None \\
\hline 17 & 7 & M & Marikina & Nasal Polyposis & $\|$ & Ethmoidectomy, uncinectomy, maxillary antrostomy & None \\
\hline 18 & 14 & $\mathrm{~F}$ & Manila & Nasal Polyposis & III & Ethmoidectomy, uncinectomy, maxillary antrostomy & None \\
\hline 19 & 14 & M & Pampanga & Nasal polyposis & III & Ethmoidectomy, uncinectomy, maxillary antrostomy & None \\
\hline 20 & 16 & $\mathrm{~F}$ & Valenzuela & Nasal polyposis & III & Ethmoidectomy, uncinectomy, maxillary antrostomy & None \\
\hline 21 & 10 & M & Albay & Antrochoanal polyp & $n / a$ & uncinectomy, maxillary antrostomy & None \\
\hline 22 & 15 & M & Quezon Prov. & Nasal polyposis & III & Ethmoidectomy, uncinectomy, maxillary antrostomy & None \\
\hline 23 & 9 & $\mathrm{~F}$ & Quezon City & Antrochoanal polyp & $\mathrm{n} / \mathrm{a}$ & uncinectomy, maxillary antrostomy & None \\
\hline 24 & 14 & M & Manila & Nasal Polyposis & $\|$ & Ethmoidectomy, uncinectomy, maxillary antrostomy & None \\
\hline 25 & 10 & $\mathrm{~F}$ & Manila & Nasal Polyposis & $\|$ & Ethmoidectomy, uncinectomy, maxillary antrostomy & None \\
\hline 26 & 13 & $\mathrm{~F}$ & Bulacan & Nasal Polyposis & III & Ethmoidectomy, uncinectomy, maxillary antrostomy & None \\
\hline 27 & 15 & M & Cavite & Nasal polyposis & III & Ethmoidectomy, uncinectomy, maxillary antrostomy & None \\
\hline
\end{tabular}




\section{Appendix B. \\ Excerpt from the \\ Jose R. Reyes Memorial Medical Center Department \\ of Otorhinolaryngology Head and Neck Surgery \\ Nasal Polyposis Form}

Department of Otorhinolaryngology Head and Surgery

Jose R. Reyes Memorial Medical Center

NASAL POLYPOSIS FORM

Patient Age Sex Hospital No. Preoperative diagnosis

\section{Mackay and Lund Staging of Rhinosinusitis}

\begin{tabular}{|c|c|c|}
\hline SINUS & Right & Left \\
\hline Maxillary & $0 / 1 / 2$ & $0 / 1 / 2$ \\
\hline Anterior Ethmoid & $0 / 1 / 2$ & $0 / 1 / 2$ \\
\hline Posterior Ethmoid & $0 / 1 / 2$ & $0 / 1 / 2$ \\
\hline Sphenoid & $0 / 1 / 2$ & $0 / 1 / 2$ \\
\hline Frontal & $0 / 1 / 2$ & $0 / 1 / 2$ \\
\hline Ostiomeatal complex & $0 / 1 / 2$ & $0 / 1 / 2$ \\
\hline TOTAL & & \\
\hline
\end{tabular}

Legend:

For the sinuses

$\begin{array}{ll}\text { 0: no opacity For the ostiomeatal complex: } & 0: \text { no obstruction } \\ \text { 1: some opacity } & 2: \text { obstructed } \\ \text { 2: total opacity } & \end{array}$

\section{Mackay and Lund Grading of Nasal Polyposis}

\begin{tabular}{|l|c|}
\hline NASAL ENDOSCOPY FINDINGS & POLYP GRADE \\
\hline No polyps & 0 \\
\hline Polyps restricted to the middle meatus & 1 \\
\hline Polyps extending below the middle turbinate & 2 \\
\hline Massive polyposis & 3 \\
\hline
\end{tabular}

\section{Reference:}

Mackay IS, Lund VJ. Imaging and Staging In Nasal Polyposis: An Inflammatory Disease and its Treatment

\section{REFERENCES}

1. Gross CW, Gurucharri MJ, Lazar RH, Long TE. Functional endonasal sinus surgery (FESS) in the pediatric age group. Laryngoscope 1989;99(3):272-275.

2. Walner D, Markey R, Jain V, Myer CM. Clinical outcome of pediatric endoscopic sinus surgery. Am J Rhinol 2002;16(3):151-154.

3. Watelet J B, Annicq B, Van Cauwenberge P, Bachert C. Objective outcome after functional endoscopic sinus surgery: prediction factors. Laryngoscope 2004;114(6): 1092-1097.

4. Ramadan $\mathrm{HH}$. Surgical management of chronic sinusitis in children. Laryngoscope 2004; 114(12):2103-2109.

5. Hebert RL, Bent JP. Meta-analysis of outcomes of pediatric functional endoscopic sinus surgery. Laryngoscope 1998. 108(6):796-799.

6. Stankiewicz J. Pediatric endoscopic nasal and sinus surgery. Otolaryngol Head Neck Surg 1995;113(3):204-210.

7. Leaper M, Dawes P. Five year audit of paediatric sinus surgery: Dunedin Hospital. Austral J Otolaryngol 2004;7(1):21-25.

8. Clary RA. Is there a future for pediatric sinus surgery? An American perspective. Int J Pediatr Otorhinolaryngol 2003; 67(1):S213-S215.

9. Clement PA, Bluestone BD, Gordts ,F, Lusk RP, Otten FWA, Goossens $H$ et al Management of rhinosinusitis in children: consensus meeting. Arch Otolaryngol Head Neck Surg. 1998;124:31-34.

10. Chang P, Lee L, Huang C, Lai C, Lee T. Functional endoscopic sinus surgery in children using a limited approach. Arch Otolaryngol Head Neck Surg.2004; 130:1033-1036.

11.Settipane GA, Chafee FH. Nasal polyps in asthma and rhinitis. A review of 6,037 patients. J Allergy Clin Immunol 1977;59(1):17-21.

12.Settipane G. Epidemiology of nasal polyps. Allergy Asthma Proceedings 1996 17:231-236.

13.Lund VJ, Kennedy DW. Staging for Rhinosinusitis. Otolaryngol Head Neck Surg 1997 117(3pt 2): 35-40.

14.Lund VJ, Mackay IS: Imaging and staging. In Nasal Polyposis: An Inflammatory Disease and Its Treatment. Edited by Mygind N, Lildholdt T. Copenhagen: Munksgaard; 1997:137-144.

15.Gysin C, Alothman G, Papsin B. Sinonasal disease in cystic fibrosis: clinical characteristics, diagnosis, and management. Pediatric Pulmonology 2000; 30:481-489.

16. Ramadan HH. Relation of Age to Outcome After Endoscopic Sinus Surgery in Children. Arc Otolaryngol Head Neck Surg 2003; 129:175-177.

17. Hopkins C, Browne J, Slack R, Lund V, Brown P. The Lund-Mackay staging system for chronic rhinosinusitis: How is it used and what does it predict?. Otolaryngol Head Neck Surg 2007; 137 (4): 555-561. 